\title{
22
}

\section{Role of Language in Identity Formation: An Analysis of Influence of Sanskrit on Identity Formation}

\author{
Varanasi Ramabrahmam
}

\section{Introduction}

The contents of Brahmajnaana, the Buddhism, the Jainism, the Sabdabrahma Siddhanta and Shaddarsanas will be discussed to present the true meaning of individual's identity and I. The influence of spirituality contained in Upanishadic insight in the development of Sanskrit language structure, Indian culture, and individual identity formation will be developed. The cultural and psychological aspects of a civilization on the formation of its language structure and prominence given to various parts of speech and vice versa will be touched upon. These aspects will be also compared and contrasted with German, French, Telugu and Hindi and their respective influence on cultural and identity formation and vice versa. A cognitive science interpretation of advaita and dvaita phases of mind and bhakti and vibhakti modes of language acquisition and communication in terms of physics and electronics will be given and be clubbed to present an inclusive and comprehensive modern scientific and social scientific understanding and interpretation of Brahmajnaana, the Buddhism, the Jainism and rest of current theistic and atheistic awareness of I and its spiritual, linguistic, cognitive scientific and rationalistic ideas and opinions. The use of this study for national integration and oneness of Indians will be highlighted. 
Language is basic to knowledge, acquisition and communication; and human emotional and intellectual identity formations. The individualism and individuality of an individual evolve more aided by language which is primary to the origin and development of culture, religion, philosophy, spirituality and knowledge. All other disciplines and faculty originate and develop through language. The disciplines and knowledge are ideas evolved through experience, thought process and intuition which owe their formation and expression to language. Language is backbone to human civilization culture and scholarship.

Later when the disciplines evolve and understanding, insight, ideas influence the individuals, the culture and knowledge influence the identity formations in the individuals. This is true to any society, nation, culture, religion, region and ideology. From that point of time, language and culture together with civilization and knowledge influence mutually and evolve with time through interactions and exchange of ideas. The identity formations sometimes change with changing times in relation to political, spiritual, social and ideological influences and innovations. An attempt is made in this article to observe and identify the influence of Sanskrit language on the identity formations of Indians and the formation of their psyche through centuries to now.

\section{Sanskrit Language, Indian Literature and Culture}

The Vedas are the first creations in Sanskrit language. The Upanishads are the end parts of the Vedas. It is well-known that Indian scientific, technological, cultural, social, political, philosophical and spiritual systems are deeply influenced Indian psyche for, for and against, the Vedas and their influence. The sanaatana dharma vouches for Vedic influence in a positive way and commends the Vedas for the fineness and refinedness of human intuition and expression of experience, divine or secular. This subtlety of human identity, the Real I, has been extensively dealt with in the Upanishads.

Some of the Upanishadic mahaa vaakyaas that depict the Real I Identity are: 


\section{Aham Brahma Asmi, Tat Toam Asi, Ayam Atma Brahma, Prajnanam Brahma, Sarvam Khalu Idam Brahma, Anando Brahma}

These sentences have been commented on from various angles of perception and experience and the intuitive seers have come up with various interpretations. Thus we have advaita of Sankara, visistaadvaita of Raamaanuja, dvaita of Madahwa and saaktaadvaita schools of theology. The advaita concept of Brahmajnaana is used and extended by Patanjali to propose and explain the theory of language of acquisition and communication-the development of Sabdabrahma Siddhanta which is later termed as sphota vaada by Bhartruhari in vaakyapadeeyam text and later grammarians have further expanded it. This language study has proposed four modes of language acquisition and communication - para (consciousness / awareness, mode of tatparata or taatparyam, the ourort and import aspects of language), pasyantee (mode of verb, artha), madhyamaa (mode of sentence, vaakya) and vaikhari (mode of expression, uchchaaranaa) making use of nirguna bhakti and vibhakti concept. A study and contemplation of all the above has made me compose the following verse in Sanskrit followed by its English translation. This briefly gives the essence of Real I Identity as envisaged by the Upanishads, Brahmajnaana, Sabdabrahma Siddhaanta and sphota vaada. The Ramayana, the Mahabharata, the Mahabhaagavata, the Panchatantra have contributed a lot to the formation and evolution of the cultural identity of an individual in influencing and shaping one's social, cultural and spiritual formation and uplift.

The normal identity of an individual is to one's gender, caste, community, region, religion, social status, educational qualifications, cultural and aesthetic tendencies, intellectual calibre and other mental merits and demerits. Thus the identity formation of an individual consists of entities I, me and mine in the worldly and secular sense.

The following chief Upanishadic maha vaakyaas are commented from psychological and cognitive scientific points of view to help in the furtherance of this understanding. 


\section{Aham Brahma Asmi I AM BRAHMAN}

The real identity of ' $\mathrm{I}$ ' is Unoccupied Awareness. ' $\mathrm{I}$ ' is not a body, person, thought or not a sense. ' $\mathrm{I}$ ' is pure consciousness. ' $\mathrm{I}$ ' is the impersonal Seer which is the source of mental energy and guide of and witness to transformation of mental energy as mental functions but unaffected by them and transcending both mental functions and their cessation.

\section{Tat Tram Asi THAT IS YOU}

Self and Pure Consciousness are same in nature, content, structure, form (function) and presence. At a given moment either self-consciousness or pure consciousness will be present. Self-consciousness is super imposition over pure consciousness. Pure consciousness is continuous, self-consciousness is transient and transitory.

Ayam Atma Brahma THIS ATMAN IS BRAHMAN

Atman is Brahman - Unoccupied Awareness -- Energy Presence without transformation.

Prajnanam Brahma PRAJNANAM IS BRAHMAN

Brahman - as Atman - Energy Presence - is Mental TimeSpace and Continuous Awareness. Prajnanam is Unoccupied (by cognitions, thoughts, cognition-related and created experiences, senses or their retrieval) Awareness in Pure Consciousness.

Anando Brahma BLISS IS BRAHMAN

Unoccupied Awareness is bliss. Unoccupied awareness is also known as pure consciousness, content-free contentment, uninvolved observation and evaluation etc.,

Atman is sat-chit-ananda. Sat is the present continuous form of the root (dhaatu) 'as' meaning 'to be' Jagat is the present continuous form of the root (dhaatu) 'jag' meaning 'to move'. Jagat forms adhyasa on sat and pure consciousness (paramaatma state) (chit) becomes self-consciousness (jeevaatma state). Both paramaatma-ego-free or ego-transcending and jivaatmaegoistic mind are present continuous forms and refer to mental functions not taking place or taking place.

Sarvam Khalu Idam Brahma ALL IDAM IS BRAHMAN

Idam, (prapancham or jagat) ( all the world - the collection of 
cognitions sensed by sense organs through the medium of manas) - is composed in, made up of, sustained by, rests in and ceases to be because of and part and parcel of psychic energy pulse generator - Atman.

WHAT IS ' $I$ '? The real identity of ' $\mathrm{I}$ ' according to Upanishads: The term ' $\mathrm{I}$ ', denotes human consciousness. Human consciousness is awareness of human mind. ' $\mathrm{I}$ ' is not a term denoting any of an individual, individual's body, selfconsciousness, the social status, age, gender, nationality, etc.,

' $\mathrm{I}$ ' is the unoccupied awareness or pure consciousness in the individual in the Jagrat Sushupti (wakeful sleep) consciousness state when peace, bliss, silence and oneness or non-duality is experienced.

' $\mathrm{I}$ ' is not a person, a thought, a sense, an experience or an understanding. ' $I$ ' is a consciousness which transcends all these and is a non-transforming seer and witness to all these and is revealed and experienced as peace or bliss or silence in wakeful sleep conscious state- the mind-transcending phase when all mental activities in the form of thoughts and senses etc, -cease to be. And one has to refer to this natural mental state when one refers to ' $\mathrm{I}$ '. ' $\mathrm{I}$ ' is unceasing, undivided continuous blissful conscious awareness. ' $\mathrm{I}$ ' or Atman is consciousness present always (in all phases of mind) and is super-imposed but untouched by mental functions during wakeful (Jagrat) and dream (Swapna) conscious states and becomes sense/mood or thought or expression. Self-consciousness arises in these two states and then ' $\mathrm{I}$ ' is identified with individual's body, sense and thoughts about I, me, mine, mental capabilities, gender, social status, age etc, and masks pure consciousness.

In deep sleep (Sushupti) conscious state (like zero in number system without value but is essential and significant) there is no awareness of the body, the within or without of the body. No 'I' expression, thought, feeling or sense or experience relating to individual exists in this mental phase.

' $\mathrm{I}$ ' or Atman is an eternal consciousness transcending the three conscious states-wakeful, dream and deep sleep- and observes all the mental activities or cessation of such activities taking place in these three mental phases. ' $\mathrm{I}$ ' is also present 
during these phases as continuous consciousness/awareness to happenings within and without of the body.

Upanishadic awareness uses the terms Atman, Brahman, Sat (Being), Chit (Pure Consciousness), Ananda (Bliss), Prajnanam (mental time-space - Unoccupied Awareness), Santhi (Peace), Maunam (Silence/Quietude/Mental Solitude) synonymously

\section{Theory of language:}

Sabdabrahma Siddhanta based on Upanishadic and Advaitic insight provides four modes of language communication and reception process; para- mode of awareness-; pasyanti -mode of verb or sense or mood - ; madhyama-mode of sentence, - and vaikhari -mode of utterance in sound form, which can be successfully used to understand human language acquisition, communication and usage processes.

These concepts have so much influenced the identity formation of Indians. Though these appear spiritual, they also are scientific.

\section{Concept of Bhakti (purport/import), verb and Vibhakti (sentence):}

Bhakti defined as

Swaswaroopaanusandhanambhaktirityabhidhiyate - tuning the mind to its origin and original form (Upanishads) or chetovrittirupetyatisthatisadaasaabhaitirityuchyate - the state in which the mind disengages itself from all vrittis (states) (Sivanandalahari) - antahakarana parinamas (manasika gathi)reversible transformations of inner mental tools-manas, buddhi, ahamkaram and chittam- and attains nivrittistate (nirmalamanasika sthiti) stays as that-is the normal or natural or ground -energy state of mind. This is the state of absence of mental functions the two-way transformation of maya/pranavam//sphota and antahkarana. This is the state of Atman or Brahman as tatparaor tatparyaor rasa.. In this state the chidabhasa or virtual chit -energy maya/pranavam/sphota - does not transform into antahkaranas (no vivartanam takes place) and no antahkarana parinama takes place. Transformation of maya/pranavam/sphota, reverse transformation 
of maya/pranavam/sphota and cessation of transformation mayal pranavam/sphota-the dvaita and advaita conscious states respectively- taking place simultaneously, consecutively and alternately is the structure, form, function, state and essence of human cognitive, language acquisition and communication processes

According to theory proposed in the above expressions the human language communication process is a combination and quick successive forward and reversible transformations of four modes i.e.,

\section{Speaker/Teacher: Language communication:}

(a) Pure Consciousness / Purport/Unoccupied Awareness (Meaningful Experience or Experienced Meaning- para) advaita sate. Bhakti state.

Dvaita (vibhakti) states:

(b) Understanding/Experience/Sense/Mood/Volition/ Intuition (pasyanti)

(c) Perception/Thinking/Feeling (madhyama)

(d) Utterance/Expression (vaikhari)

Knower/Listener/Learner: Language learning/acquisition and understanding:

Dvaita (vibhakti) states:

(a) Knowing (through sense organs)-vaikhari

(b) Perception/Thinking - madhyama

(c) Understanding/Experience/Sense/mood/Volition/ Intuition -pasyanti

(d) Pure Consciousness / Purport (Meaningful Experience/ Experienced Meaning)/Unoccupied Awareness- para. Advaita state.

The concept of soonyam: Use in Mathematics, Physics, Vedanta and Cognitive Science:

The Sanskrit word soonyam has three important meanings - zero, vacuum and state of cessation of mental functions. These are elaborated.

\section{Mathematics:}

Number system is a part of Mathematics. Zero plays a significant 
place in number system. As we know, when zero is put on the right hand side of a digit the value of the digit increases. The place values also owe their being to zero and the understanding of nature and the value of zero. As is known 'zero' was proposed by Indian Mathematicians. Zero has 'no value'. The ABSENCE of value makes zero significant and highly useful. Zero is used both by scientists and lay men with equal felicity and benefit. Zero plays important role both in sciences and ordinary day to day activities.

\section{Physics and Natural Sciences}

Physics is one of the Natural Sciences. Matter, Energy, Space and Time play chief roles in this branch of knowledge. Space contains matter and energy and the actions and interactions concern them. Space can exist without the presence of matter or energy. Space bereft of matter and energy is called Vacuum.

Thus Vacuum is ABSENCE of matter or energy. Because of the Vacuum matter (energy) can be, move and transform. If Vacuum is not, physical, chemical or biological matter cannot exist and processes cannot take place. For the being cessation of matter Vacuum is necessary. Evolution, Sustenace and Dissolution of material world and its being and non-being is based on the presence of Vacuum. Vacuum holds matter and its transformations. Thus Vacuum (ABSENCE of matter) is the stage on which natural scientific transformations are enacted.

\section{Vedanta}

Vedanta is a philosophical system of ancient Indian thought. Vedanta is integrated psychology and is a science of mind. The definition, origin, structure, function, cessation and control of mind and its activities constitute the subject matter of Vedanta. State of awakening, state of dream and state of deep sleep are the conscious states of mind. Deep sleep state is a state of cessation of mind and its activities. During this phase of mind cognition of objects or object - created experiences are not sensed. Mind remains absorbed in its source, the SELF. State of SELF is the natural and original state of mind. This is a serene state. 
This is a blissful state of mind. Energy from SELF is responsible for the mental Activities and their observations as a witness. Experiencing the thought - free and object experience-free state with awareness is a wakeful sleep and without awareness is deep sleep. This is the phase of ABSENCE of activities of mind. This is the awareness phase or conscious thought and object - experience free phase. This is the state of SELF in the natural state of mind. This state is also called state of timelessness, state of cognition free unoccupied awareness, state of liberation 'Turiya' state, or thought, object -experience transcendent state, state of silence or blissful state.

\section{Cognitive Science}

The process of Knowing or (learning) is a combined activity of sense organs, mind and action organs. Knower, Knowledge and the Known are the inherent divisions of this process. The awareness as these three divisions is known as TRIPUTI. Where and when the awareness of these three divisions (TRIPUTI) coalesces and the consciousness of cessation of divisions and undivided pure consciousness glows. This experience is experienced, that is the state of Unoccupied awareness. This is the eternally present Being - Unoccupied Awareness - Bliss state of the SELF, the Jagrat - Sushupti state.

The state of lack of consciousness of 'TRIPUTI' is referred to Absence of object cognition state or 'Soonyam' by Buddhists. The same state is referred to as acquired or inherent Knowledge and object experience transcendent state with full awareness, state of silence, state of liberation, state of Subject - knowledge - object division consciousness transcendent state, state of devotion and the like terms by the Vedantins. This is also known as thought free, object-experience free conscious state or Divine Consciousness state.

Vivartanam is the type of change that maya/sphota undergoes while sristi (creation of mental impressions or mental world during knowledge and language acquisition and communication) takes place. When sristi is being created or is in the dristi (Conscious awareness), we are mentally functioning. When sristi is in the awareness a veil is formed on dristi and 
creates adhyasa. According to Advaita thought only two mental situations are available for humans in the consciousness of the Atman. The situations are nidra or sristi. Nidra corresponds to the sushupti state of consciousness or phase of mind. During this phase of mind, all mental functions cease to be in the awareness and maya, whose transformations these mental functions are, becomes nirvishaya suddha vasanaa pravaaham. During this phase of mind maya does not bifurcate as divyam (jnanasakti) and swaram (pranasakti) as in jagrat and swapna conscious states and both sense and actions organs remain dormant and functionless.

The gist of all above expressions and discussions is:

Consciousness (Being-Sat) Awareness (Becoming-idam)

Speaker: Modulation-purodhana

Brahman/Atman chidaabhaasa/maya/pranavamantahkarananikarmendreyani/jnaanendrayani

Import experience/understanding/insight feeling/thought/ perception actions / reactions/ cognitions

Vivartanam-Reversible Becoming

Bhakti sphota+icccha/arthasaktivibhakti/jnnanasaktiucchaarana/kriyasakti

Para/tatpara/Tatparyapasyantimadhyamavaikhari

Purport mood/urge/sense/verb sentence/subject-verb-object sentence in sound form tirodhana- Demodulation: Listener

\section{Later Influences}

Thus all of us know the various texts available in Sanskrit language relating to all human endeavours from spirituality to medicine to astronomy to mathematics to various disciplines and technologies. All these have been useful to teach and learn those disciplines and also in influencing the psyche of Indians.

The Buddhism, the Jainism, the Chaarvakism, the social movements of later regional seers like Raamaanuja, Basaveswara, and like many devotees of Vishnu, Siva, Sakti, throughout India as reformation movements have contributed to the evolution of Indian culture. They made use of regional languages to express themselves. Then recently Narayana Guru, the Marxism, and other related rationalism have had tremendous impact on the minds and hearts of Indian through 
these decades. The evolution of Ambedkarism and social justice affiliations are recent social and political "emancipations". Unfortunately some of these later influences and identities have sown seeds of division, discord to the extent of disowning nationalism and the identities are blurred. The carefully nurtured concept of "vasudhaiva kutumbakam" is dethroned and is missing.

\section{Notional Observations About Some Other Languages and Mutual Influence on Culture}

Telugu, Kannada, Malayalam though are termed as Dravidian languages have plenty of Sanskrit vocabulary and Sanskrit language grammatical influence in the form of division into cases (vibhakti) and other elements like sandhi, samaasa, alamkaaraas, dhwani and karakaa. Sanskrit works from all disciplines have been translated into these languages and the spirit of Sanskrit language and culture has been imbibed by these regional cultures. It is well-known that English, German, French, Russian like European languages are Indo-European languages having similarities with the Sanskrit language. The Indian languages like Hindi also belong to this family of languages. Many words in these languages have similar roots.

The nature of German race is absorbed into their language by writing the nouns starting with capital letter wherever they occur in the sentence and whatever type of noun it is. Thus giving importance to nouns can be termed as the dominating spirit of Germans. The French language is so aesthetic that they give importance to adjectives. And also French language has a separate tense and conjugation for the verb rêver - to dream, showing their love to dream And French people do not pronounce all the letters present in the word showing their carefree nature. Whereas Germans pronounce all the letters present in the word showing their particularity and definiteness.

Also the German word-endings change according to gender, number and case; similar to Sanskrit and south Indian languages. Not only Indian spiritual thinking in the form of Brahmajnaana provided elements of cognitive science but also the theory of language acquisition and communication. The 
grammatical condition that the adjectives must take endings as the number, gender, case of Noun is similar to theistic visistaadvaita proposition that the individual (jeevaatma) is also same as Brahman (the Lord Vishnu here) viseshana-viseshya nyaaya. Thus spirituality and philosophy has also influenced reversely the form, structure and function of Sanskrit language and provided the necessary theories.

\section{Conclusion}

Thus Sanskrit language has contributed immensely and profoundly in the identity formation of Indians and their psyche through all disciplines of human endeavour. The Upanishads have given the true insight of the meaning and nature of $I$. The me, mine are discouraged so that $\mathrm{I}$ is identified with Consciousness or Unoccupied awareness in its original form which is common to all human beings and their me, mine are superimpositions over this spiritually and scientifically proved and stated real identity of I sans me and mine.

The negation of secular or worldly identity of an individual is the essence of Upanishadic teaching. This had had tremendous influence on Indian psyche and transcending the worldly happenings and behaving with equanimity of mind has been the norm thus being able to face the vicissitudes of life with dignity and calmness. In addition all the epics, panchatantra, jaataka tales and later wisdom through Sanskrit and through regional languages under the influence of the Buddhism, the Jainism in translated form and also influencing the writings in regional languages.

Identity formation with nation and time-tested useful culture as initiated and advanced through all literary, medical, grammar texts, fine-arts, philosophical and spiritual creations in Sanskrit and regional languages is gift of Sanskrit to India and its citizens. It would be a remedy to all our social, political, regional, religious and ideological ills if the identity formation is done as envisaged by ancient Indians. 


\section{NOTE}

This chapter consolidates the evolution of my thoughts and insights over several years and correlates to the idea of identity formation as can be seen through my earlier presentations and publications, references to which have been amply provided below.

\section{REFERENCES}

Radhakrishnan, S. The Principal Upanishads. Indus, An imprint of Harper Collins Publishers, India, 1994.

Ramabrahmam, V. "The Significance and Use of Absence." Bharatiya Bauddhika Sampada November (2003), 7.

Ramabrahmam, V. Human cognitive process- An ancient Indian model, Proceedings of the International Vedic Conference on Contribution of Vedas to the World, Haridwar, 2005.

Ramabrahmam, V., Being and Becoming: A Physics and Upanishadic Awareness of Time and Thought Process, Ludus Vitalis, XIII Num. 24, (2005): 139-154.

Ramabrahmam, V., Elements of cognitive sciences and artificial intelligence in Gayatri Mantra - Proceedings of National seminar on Bharatiya Heritage in Engineering and Technology at Department of Metallurgy and Inorganic Chemistry, I.I.Sc., Bangalore, India, (2006) 249-254.

Ramabrahmam. V. “The Science of Human Consciousness." Ludus Vitalis, XV, No. 27, (2007): 127-142

Ramabrahmam, V., A Physics and Communication Engineering Insight of Brahma Jnaana, Presentation at Eighteenth International Congress of Vedanta at University of Massachusetts-Dartmouth, MA, July 16-19, 2009.

Ramabrahman, V. Modes of language acquisition and communication. Video presentation at WAVES conference at Boston, USA, July 13-15, 2012.

Ramabrahmam, V, Paper presented at Introspections on Buddhist Traditions, 7-9, September, 2012. School of Buddhist Studies and Civilization, GBU University, Greater Noida, U.P. Title of paper: "A modern scientific insight of Soonya Vaada of Buddhism: Its implications to delineate origin and role of rationalism in shaping Buddhist Thought and life," 2012.

Ramabrahmam, V. Paper presented at International Conference on Indic Studies, 2013, on the theme - Ancient Indian wisdom and modern world, March 29-31, 2013, Delhi, India. Sub-theme: Ancient Indian Vision and Cognitive Science. Title: "A cognitive science 


\section{Linguistic Foundations of Identity}

correlation of the meaning of padaartha in relation to human consciousness, mind and their functions", 2013.

Ramanuja Tatacharya, N.S. Sabdabodhameemamsa-An Inquiry into Indian

Theories of Verbal Cognition Part I - The Sentences and its Significance. Institut Francais De Pondichery, Pondicherry - Rashtriya Sanskrit Sansthan, New Delhi, 2005.

RamanujaTatacharya, N.S. Sabdabodhameemamsa-An Inquiry into Indian Theories of Verbal Cognition Part II - Case Terminations and their Significance. Institut Francais De Pondicherry, Pondicherry, Rashtriya Sanskrit Sansthan, New Delhi, 2006.

Subbarao, V., The philosophy of a Sentence and its parts, Munshiram Manoharlal, New Delhi, 1969.

Bhartruhari. Vakyapadeeyam. Telugu Akadami, Hyderabad, 1974.

Balasubrahmanian, S.N. An 'intelligent' Machine?, (private communication), 2008.

\section{Appendix I:}

My following depiction in verse form informs that the real identity of an individual is mere consciousness, unoccupied awareness, the timespace- and mind-transcendence.

Koham?

Raga dveshou sukha dukhe yat karoteeti dvandvow Tat mama maanasam praapnuyaat yadaa samah chet tadaa koham?

Naasti me snehahahh naasti me mohaha naaham taptah vishayaaihi aharaham

Swapnaha vaa sushuptihi naasti kadaa naasti kaalajnaanam asti prajnaanam sadaa

Drushtaa mayaa jagatee panchabhootaatmika anubhavaha tu na jaagrutaha tayaa mithyayaa

Na drusyate yat kimchadapi sukhapoornaa mama sthithihi

Nirmala kaaaaramiva antarangam nischalamasti vinaa maanasam

Bhayabhraantaha naasmi bhavabanhaani naa santi me gatataha klesaha bhavishyatataha aantolanam n stou saagare leena nadee mama ahamkaaram priya parishwangasthitaa sakhee mama maanasam

bhaavajharee gunaraahityena sthagitaa sthitaa tu aanandnubavalaharee 
Vishayavaasanaarahita vyomaha drushtihi mama savaadaa aham aataamaa raamaha

satatavaagdhaara mounamasmi pravahati mayi srutisrutavaaksaaram kaalagatihi na jnaayate mayaa suddhoham sphuranapoora hrudayamaham

Maanasam mam kaadaasvasthitim praapnuyaat tada idaaneem

Jnaana sikhaa vaa prajnaanakhanihi saantasvaroopaha vaa aananda lahari

Koham? Kaa mama sthitihi?

Satata saantapravaahamasmi 